\title{
Pricing and Reimbursement of Biosimilars in Central and Eastern European Countries
}

\begin{abstract}
Pawel Kawalec ${ }^{1 *}$, Ewa Stawowczyk ${ }^{1}$, Tomas Tesar ${ }^{2}$, Jana Skoupa ${ }^{3}$, Adina Turcu-Stiolica ${ }^{4}$, Maria Dimitrova ${ }^{5}$, Guenka I. Petrova ${ }^{5}$, Zinta Rugaja ${ }^{6}$, Agnes Männik ${ }^{7}$, Andras Harsanyi ${ }^{8,9}$ and Pero Draganic ${ }^{10}$

${ }^{1}$ Institute of Public Health, Faculty of Health Sciences, Jagiellonian University Medical College, Kraków, Poland, ${ }^{2}$ Department of Organisation and Management in Pharmacy, Faculty of Pharmacy, Comenius University in Bratislava, Bratislava, Slovakia, ${ }^{3}$ CZECHTA Institute o.p.s., Prague, Czechia, ${ }^{4}$ Faculty of Pharmacy, University of Medicine and Pharmacy of Craiova, Craiova, Romania, ${ }^{5}$ Department of Organization and Economy of Pharmacy, Faculty of Pharmacy, Medical University, Sofia, Sofia, Bulgaria, ${ }^{6}$ Senior Expert at The National Health Service, Riga, Latvia, ${ }^{7}$ Institute of Family Medicine and Public Health, University of Tartu, Tartu, Estonia, ${ }^{8}$ National Health Insurance Fund of Hungary, Budapest, Hungary, ${ }^{9}$ Department of Health Policy and Health Economics, Eötvös Loránd University, Budapest, Hungary, ${ }^{10}$ Croatian Agency for Medicinal Products and Medical Devices, Zagreb, Croatia
\end{abstract}

OPEN ACCESS

Edited by:

Claudio Bucolo,

University of Catania, Italy

Reviewed by:

Mihajlo Jakovljevic,

University of Kragujevac, Serbia

Ana V. Pejcic,

University of Kragujevac, Serbia

*Correspondence:

Paweł Kawalec

pawel.kawalec@uj.edu.pl

Specialty section:

This article was submitted to

Pharmaceutical Medicine and

Outcomes Research,

a section of the journal

Frontiers in Pharmacology

Received: 10 March 2017

Accepted: 05 May 2017

Published: 08 June 2017

Citation:

Kawalec P, Stawowczyk E, Tesar T,

Skoupa J, Turcu-Stiolica A

Dimitrova M, Petrova Gl, Rugaja Z, Männik A, Harsanyi $A$ and Draganic $P$ (2017) Pricing and Reimbursement of

Biosimilars in Central and Eastern European Countries.

Front. Pharmacol. 8:288.

doi: 10.3389/fphar.2017.00288
Objectives: The aim of this study was to review the requirements for the reimbursement of biosimilars and to compare the reimbursement status, market share, and reimbursement costs of biosimilars in selected Central and Eastern European (CEE) countries.

Methods: A questionnaire-based survey was conducted between November 2016 and January 2017 among experts from the following CEE countries: Bulgaria, Czech Republic, Croatia, Estonia, Hungary, Latvia, Lithuania, Poland, Slovakia, and Romania. The requirements for the pricing and reimbursement of biosimilars were reviewed for each country. Data on the extent of reimbursement of biologic drugs (separately for original products and biosimilars) in the years 2014 and 2015 were also collected for each country, along with data on the total pharmaceutical and total public health care budgets.

Results: Our survey revealed that no specific criteria were applied for the pricing and reimbursement of biosimilars in the selected CEE countries; the price of biosimilars was usually reduced compared with original drugs and specific price discounts were common. Substitution and interchangeability were generally allowed, although in most countries they were at the discretion of the physician after a clinical assessment. Original biologic drugs and the corresponding biosimilars were usually in the same homogeneous group, and internal reference pricing was usually employed. The reimbursement rate of biosimilars in the majority of the countries was the same and amounted to $100 \%$. Generally, the higher shares of expenditures were shown for the reimbursement of original drugs than for biosimilars, except for filgrastim, somatropin, and epoetin (alfa and zeta). The shares of expenditures on the reimbursement of biosimilar products ranged from 8.0\% in Estonia in 2014 to 32.4\% in Lithuania in 2015, and generally increased in 2015. The share of expenditures on reimbursement of biosimilars in the total pharmaceutical 
budget differed between the countries, with the highest observed value for Slovakia and Hungary and the lowest-for Croatia.

Conclusions: The requirements for the pricing and reimbursement of biosimilar products as well as the access of patients to biologic treatment do not differ significantly between the considered CEE countries. Biosimilar drugs significantly influence the reimbursement systems of these countries, and the expenditure on the reimbursement of biosimilars is increasing as they are becoming more accessible to patients.

Keywords: biosimilar pharmaceuticals, pricing, reimbursement, original products, interchangeability

\section{INTRODUCTION}

Biologics are complex, protein-based drugs used in various diseases, including diabetes (insulins), inflammatory diseases, and cancers. They are produced in living organisms, such as bacteria, yeast, animals, or plants. The introduction of biologics has been a major breakthrough in the treatment of numerous conditions, but the drugs are often expensive (Mulcahy et al., 2014; Ornes, 2015). A biosimilar is a biological product that is approved for use on the basis of high similarity to an original biological product, known as a reference product or originator drug, and that shows no clinically meaningful differences in terms of safety and effectiveness from the original product. Only minor differences in clinically inactive components are acceptable, and a biosimilar provides the same clinical benefits as an original drug that is already on the market. Pharmaceutical companies can release biosimilar products after a patent on a particular biologic drug has expired. Over the past decade, over 80 biologic molecules have been launched globally (IMS, 2016). By 2020 the global market of biologic medicinal products is projected to exceed 390 billion USD and its value is estimated to account for up to $28 \%$ of the global pharmaceutical market. By this time, biosimilar products will have the potential to enter markets as follow-ons to a number of key biologics which have the current sales of more than 40 billion EUR. Almost 50 distinct biosimilars are currently in development (IMS, 2016). Biosimilars have the potential to reduce the cost of treatment similarly to generics in the case of traditional, chemically synthesized drugs. By ensuring greater access to the same substance at a lower cost, they will greatly affect the current situation of pharmaceutical and insurance companies, as well as patients themselves (Ornes, 2015; IMS, 2016). It was estimated that the cost-saving potential of biosimilars could exceed 44.2 billion USD over 10 years (Mulcahy et al., 2014). According to another source, the costsaving potential of biosimilars in the European Union (EU) and the United States (US) could equal even more than 50 billion EUR over 5 years and reach even 100 billion EUR in 2020 (IMS, 2016).

Biologics are becoming increasingly important on the pharmaceutical market. They are listed among 10 key therapies in the world, and their sales volumes largely increased in the period from 2009-2014. In 2009 only 2 biologics were among 10 key therapies in the world: etanercept and infliximab (listed the sixth and seventh, respectively). But in 2014 there were already 5 biologics: adalimumab (first), insulinum glargine (second), etanercept (fifth), infliximab (seventh), and rituximab (tenth)
(Long, 2015). In Germany the position of biologics is even higher: in 2014 the top 5 key therapies were biologics (adalimumab, bevacizumab, etanercept, trastuzumab, and rituximab), and there were 2 additional biologics, infliximab and interferon beta-1a, listed as the ninth and tenth, respectively. There were only 3 small-molecule products listed in the top 10. Such situation has been observed since 2009 when 5 out of the top 10 products were biologics (adalimumab, etanercept, interferon beta-1a, enoxaparin, and trastuzumab) (Long, 2015). Several biologics will lose patent exclusivity between the years 2015 and 2020 (see Table 1).

Sales of the 8 top-selling biologics which will lose patent protection by 2020 are enormous. They equalled 42.3 billion EUR in September 2015 in 5 EU countries (France, Germany, Italy, Spain, United Kingdom) and in the US (IMS, 2016) and 60.3 billion USD globally in the whole US and EU (Long, 2015).

The introduction of biosimilars has increased the access to effective treatment by reducing costs, thus significantly increasing the use of biologics. The increase was the highest in countries with a previously limited access to these drugs, such as Romania, Bulgaria, and Czech Republic (IMS, 2016). The average price reduction of biologics due to introduction of biosimilars was $27 \%$ in the EU in general, and $50 \%$ in Romania, Bulgaria, and Czech Republic. The average increase in sales was 16 and 263\%, respectively (IMS, 2016). The introduction of biosimilars has also increased the number of available treatment options.

In Europe, there is no universal approach to the reimbursement of biosimilars. Their pricing and the extent of price reduction can vary significantly between countries. The highest price reduction of biosimilars compared to original drugs was observed in Germany (55\%) and France (39\%), while it was lower in Scandinavian countries, ranging from 25 to $29 \%$ (IMS, 2016).

The aim of our study was to review the requirements for the reimbursement of biosimilars in selected CEE countries as well as to perform relative comparisons to assess differences in the market share and reimbursement costs of biosimilars between those countries.

\section{MATERIALS AND METHODS}

The study was conducted in a period from November 2016 to January 2017. Experts from participating countries including Bulgaria, Czech Republic, Croatia, Estonia, Hungary, Latvia, 
Lithuania, Poland, Slovakia, and Romania provided indepth data, valid for sophisticated assessment of biosimilars environment in reference countries, their pricing and reimbursement policy of biologics in their countries, as well as data on coverage for specific biologics, separately for original drugs and biosimilars. In order to facilitate comparisons between countries, reviews were based on a standardized questionnaire which included all necessary aspects covered by the project.

In our study, at least one leading national expert (scientist or government official) participated, who was involved in biosimilars pricing and reimbursement policy, representing each of considered countries; collection as well as assessment of data was conducted under supervision of coordinator of the whole project.

The first part of the survey included questions on the pricing and reimbursement of biologics in a given country, while the second part required providing data on the reimbursement status and level for each individual biologic drug. Reimbursement status data are valid for the fourth quarter of the year 2016; data on reimbursement costs of biologic drugs (separately for original drugs and biosimilars if country-specific data was available) in the years 2014 and 2015 were also collected along with the corresponding data on the total pharmaceutical and public health care budgets.

In our analysis, we included all currently approved biosimilars (25 product names) for 10 biologic drugs: enoxaparin sodium, epoetin alfa, epoetin zeta, etanercept, filgrastim, follitropin alfa, infliximab, insulin glargine, somatropine, and teriparatide according to the European Medicines Agency (EMA) official website (European Medicines Agency, 2017).

The questionnaires were distributed and responses were collected by e-mail. E-mail was also used to contact respondents in case of any doubts or additional questions.

The statistical analysis of obtained data was performed. The following values were calculated: the share of expenditure on the reimbursement of biosimilars and original drugs separately for each biologic and for each country, the share of expenditure

TABLE 1 | Patent expiry dates of biologics (Derbyshire, 2015).

\begin{tabular}{|c|c|c|}
\hline Biologics & $\begin{array}{l}\text { Patent expiry date } \\
\text { in the EU }\end{array}$ & $\begin{array}{c}\text { Patent expiry date } \\
\text { in the US }\end{array}$ \\
\hline Humira ${ }^{\circledR}$ (adalimumab) & 2018 & 2016 \\
\hline Avastin $^{\circledR}$ (bevacizumab) & 2022 & 2019 \\
\hline Enbrel $^{\circledR}$ (etanercept) & 2015 & 2028 \\
\hline Remicade $^{\circledR}$ (infliximab) & 2015 & 2018 \\
\hline NovoLog ${ }^{\circledR} /$ NovoRapid ${ }^{\circledR}$ (insulin aspart) & 2011 & 2014 \\
\hline Lantus $^{\circledR}$ (insulin glargine) & 2014 & 2014 \\
\hline Avonex $^{\circledR}$ (interferon beta-1a) & 2015 & 2015 \\
\hline Tysabri $^{\circledR}$ (natalizumab) & 2015 & 2015 \\
\hline Xolair $^{\circledR}$ (omalizumab) & 2017 & 2017 \\
\hline Neulasta ${ }^{\circledR}$ (pegfilgrastim) & 2017 & 2015 \\
\hline MabThera ${ }^{\circledR}$ (rituximab) & 2013 & 2016 \\
\hline Lucentis ${ }^{\circledR}$ (ranibizumab) & 2022 & 2020 \\
\hline Herceptin ${ }^{\circledR}$ (trastuzumab) & 2014 & 2019 \\
\hline
\end{tabular}

on reimbursement of biosimilars as percentage of the total pharmaceutical budget and total health care budget in the year 2014 and 2015.

\section{RESULTS}

\section{A Review of Pricing and Reimbursement of Biosimilars in CEE Countries}

Selected issues relating to the reimbursement and pricing of biosimilars in the CEE countries were summarized in Table 2. None of the countries were shown to have a specific price negotiation procedure exclusively for biosimilars, except Lithuania, which applied a specific pricing pathway for outpatient care.

We found specific price discounts for the first or subsequent biosimilars (or both) submitted for reimbursement in all countries. The discount ranged from 5 to $30 \%$ of the price of the original drug. In Hungary, the first biosimilar entering the market has to offer a price reduction of $30 \%$ in relation to the ex-factory price of the original product (ESzCsM Decree, 2017), the second - an additional 10\% reduction of the ex-factory price of the first biosimilar product, and the third-a further $10 \%$ reduction of the ex-factory price of the second biosimilar product. Any additional product has to enter the market with a lower ex-factory price than the cheapest reimbursed product.

The reimbursement criteria for biosimilars were generally similar to those for other generic products, and there were no specific criteria exclusively for biosimilars in any of the countries (see Table 2). In Bulgaria the criteria for reimbursement were as follows: availability of an alternative medicine for the treatment of the disease for which the medicinal product is indicated, efficacy and therapeutic effectiveness, safety, appropriate pharmacoeconomic indicators, as well as a positive reimbursement status in at least 5 other EU countries ${ }^{1,2}$. In Romania each evaluation criterion had its own number of points, and the criteria were as follows: health technology assessment (HTA) based on therapeutic benefit (max. 15 points), HTA based on number of EU countries with a positive reimbursement status (max. 25 points), Positive Assessment Report issued by the National Agency for Medicines and Medical Devices (max. 45 points), and therapy costs-direct costs (max. 30 points). The maximum was 145 points and conditional reimbursement is for 60-79 points (Ministry of Health, 2013, 2014).

The price of biosimilars is regulated by the tendering system/procedure in the majority of the countries, except for Estonia and Lithuania where it applies only to inpatient care. In Slovakia, Poland, and Hungary, the main criterion for tendering is price. In Czech Republic, tenders are rarely established by the State Institute for Drug Control (SUKL) or health insurance funds, because there is a mandatory reassessment

\footnotetext{
${ }^{1}$ Annex I and Annex II of the Positive Drug List of Bulgaria. Available online at: www.ncpr.bg (Accessed February13, 2017).

${ }^{2}$ Ordinance on the Terms, Rules and Procedure for Regulation and Registration of Prices for Medicinal Products/30.04.2013, Ammended and Supplemented, SG 8 of 24.01.2017. Available online at: http://www.ncpr.bg/ (Accessed February13, 2017).
} 


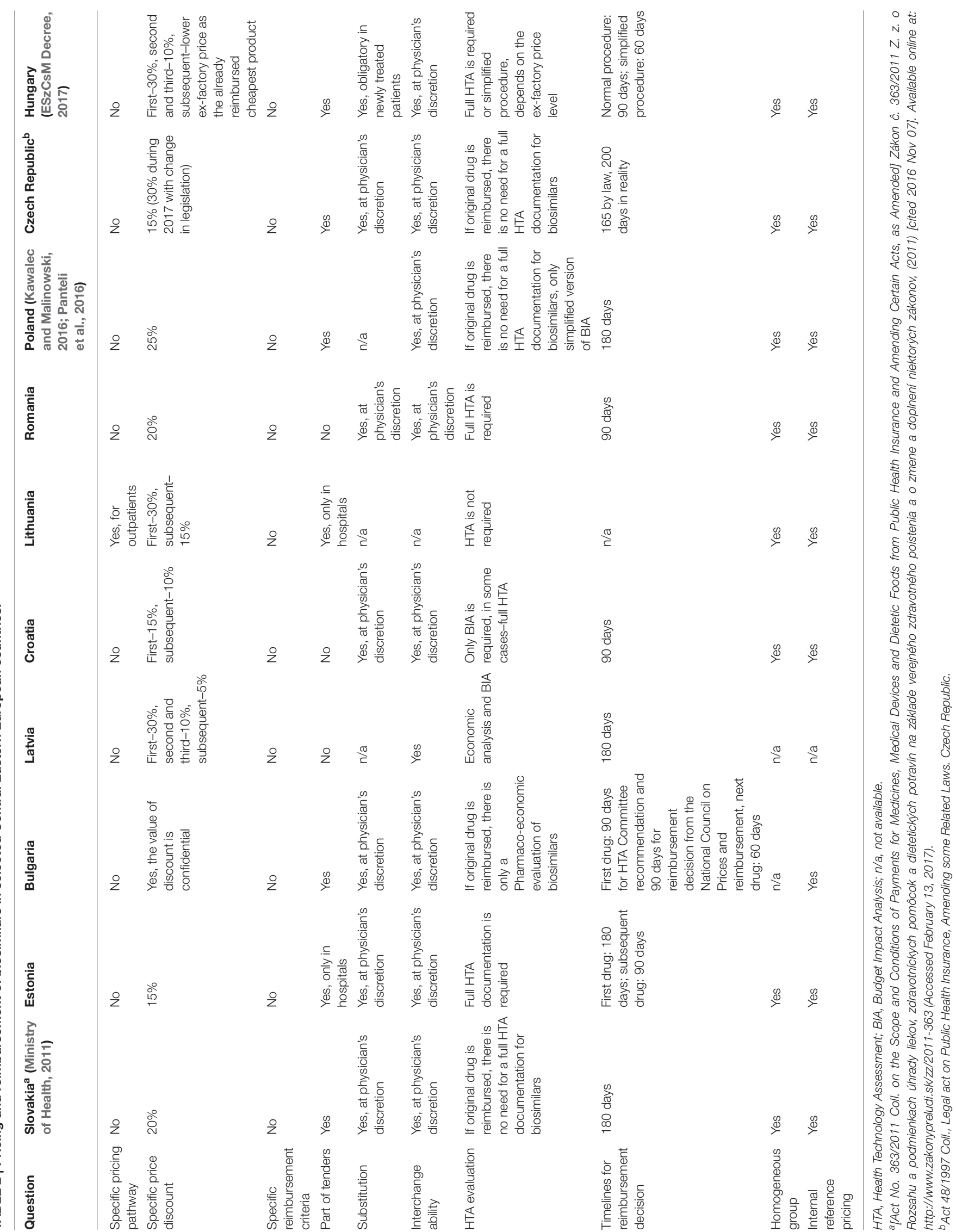


of the reimbursement level for all products within a reference group, based on the tender offer. This means that following a tender offer all products within the reference group will undergo a reassessment (usually a reduction) of reimbursement based on the tender price. However, tenders are frequently used for inpatient drugs. In Latvia, Croatia, and Romania, tendering is not used for biosimilars.

Therapeutic substitution, which is a change of one substance (e.g., infliximab) for another substance (e.g., adalimumab) with a similar therapeutic effect and indication, was allowed only at the discretion of the physician, except for Lithuania, Latvia and Poland, where substitution was not allowed. Interchangeability, which means using one biosimilar in place of another one [e.g., Remsima (infliximab) in place of Inflectra (infliximab)], was generally allowed but only at the discretion of the physician. The exception was Lithuania where interchangeability was not allowed. No legal basis for therapeutic substitution or interchangeability of biosimilars was reported for any of the countries.

If a given biosimilar is the first drug with a particular active substance to be reimbursed, a full HTA dossier is obligatory in all countries except Lithuania. If the original drug or another biosimilar with the same active substance has already been reimbursed, usually there is no need for full HTA documentation; in Poland only simplified Budget Impact Analysis (BIA) should be submitted (Kawalec and Malinowski, 2016; Panteli et al., 2016). In Bulgaria, if there is already the same International Nonproprietary Name (INN) on the Positive Drug List, the biosimilar product should be evaluated by the National Council on Prices and Reimbursement, providing the final reimbursement decision. In Croatia only BIA is required for biosimilars, and in certain cases, the Croatian HTA agency performs HTA evaluation.

The timelines for pricing and reimbursement decisions differed between the countries and ranged from 60 to 200 days, but in the majority of the countries, a 180-day deadline for decision-making process was applied according to the EU Transparency Directive. In Hungary (ESzCsM Decree, 2017), it depends on the type of the procedure applied: in the case of a standard procedure, it usually takes 90 days to make a reimbursement decision, and in the case of a simplified procedure-only 60 days. In Bulgaria since 2016 the procedure for new INNs is extended to 180 days as in the reimbursement decision process a HTA Committee is involved. Within 90 days the HTA Committee should issue recommendation for inclusion in the Positive Drug List. If the decision is positive, the National Council on Prices and Reimbursement of Medicinal Products should issue the final reimbursement decision in 90 days. In case there is already the same INN on the Positive Drug List the National Council on Prices and Reimbursement should issue the reimbursement decision in 60 or 90 days like in Hungary and Estonia, respectively (Regulation of Ministry of Social Affairs, 2017).

In all countries, except Bulgaria and Latvia which did not provide specific information, biosimilars belong to a homogenous group of drugs. In Estonia, the homogenous group is made with a transitional period of 3 months. Internal reference pricing was used in all countries, except Latvia for which this particular data is not available.

\section{Reimbursement Status of Biologics}

We analyzed the reimbursement status of selected biologic drugs for which biosimilars are available, separately for each country, and indication. The level of reimbursement (the percentage of the drug price covered by public payer) per drug and country is shown in Table 3.

The biologic drugs were reimbursed in the majority of cases in all countries: filgrastim for neutropenia or febrile neutropenia; etanercept for rheumatoid arthritis, juvenile idiopathic arthritis, psoriatic arthritis, and ankylosing spondylitis; infliximab for all approved indications (except plaque psoriasis in Latvia); insulin glargine for diabetes mellitus; and somatropin for growth disturbance or growth hormone deficiency. Epoetin alfa and epoetin zeta was not reimbursed in Estonia, while in each other country epoetin alfa or zeta was financed from public funds in at least one indication (no data for Lithuania). Etanercept was not reimbursed in Latvia in the treatment of axial spondyloarthritis and plaque psoriasis. Enoxaparin for thromboembolic disorders of venous origin was reimbursed in all countries except Lithuania. Follatropin alfa and teriparatide are reimbursed in majority of countries-only in Romania follitropin alfa was not financed from public funds, and teriparatide was not reimbursed in Estonia and Poland (no data for Lithuania).

Inpatient drugs generally had $100 \%$ reimbursement (filgrastim, etanercept, infliximab, epoetin alfa, and zeta products), although for insulin glargine the reimbursement rates ranged from 30 to $100 \%$. In Hungary filgrastim, somatropin, epoetin alfa, and zeta products were reimbursed in 100\% but a prescription fee per unit of 300 HUF (about 1 EUR) was covered by the patient. Etanercept and infliximab products were reimbursed in $100 \%$ in 2014 and 2015 through itemized payment in inpatient care. The reimbursement of filgrastim was $100 \%$ in all other countries, except Poland, where it was diversified and depended on the way of reimbursement. In the case of ambulatory drugs, patients had to pay a lump sum for a package of the product, but reimbursement was $100 \%$ for inpatient drugs. The level of reimbursement for enoxaparin was $100 \%$ in most countries except Poland, where the patient paid a lump sum, Latvia and Hungary, where the patient had to pay 25 and $10 \%$ of the price, respectively. In Slovakia selected insulin glargine, somatropin, and enoxaparin products were fully reimbursed, and for the remaining products patients had to pay from 18.3 to $32.3 \%$ of the price. Follitropin alfa had different level of reimbursement across countries-from 25\% in Hungary to $100 \%$ in Latvia, Croatia, Bulgaria, and Czech Republic. Similar situation was observed in case of teriparatide-the level of reimbursement varied from 50\% (Bulgaria for outpatients, Latvia) to $100 \%$ (Croatia, Bulgaria for inpatients, Romania, Czech Republic).

\section{Reimbursement Costs}

The total expenditure on the reimbursement of biologic drugs in the CEE countries was 397,097,152 EUR in 2014 and 411,433,628 


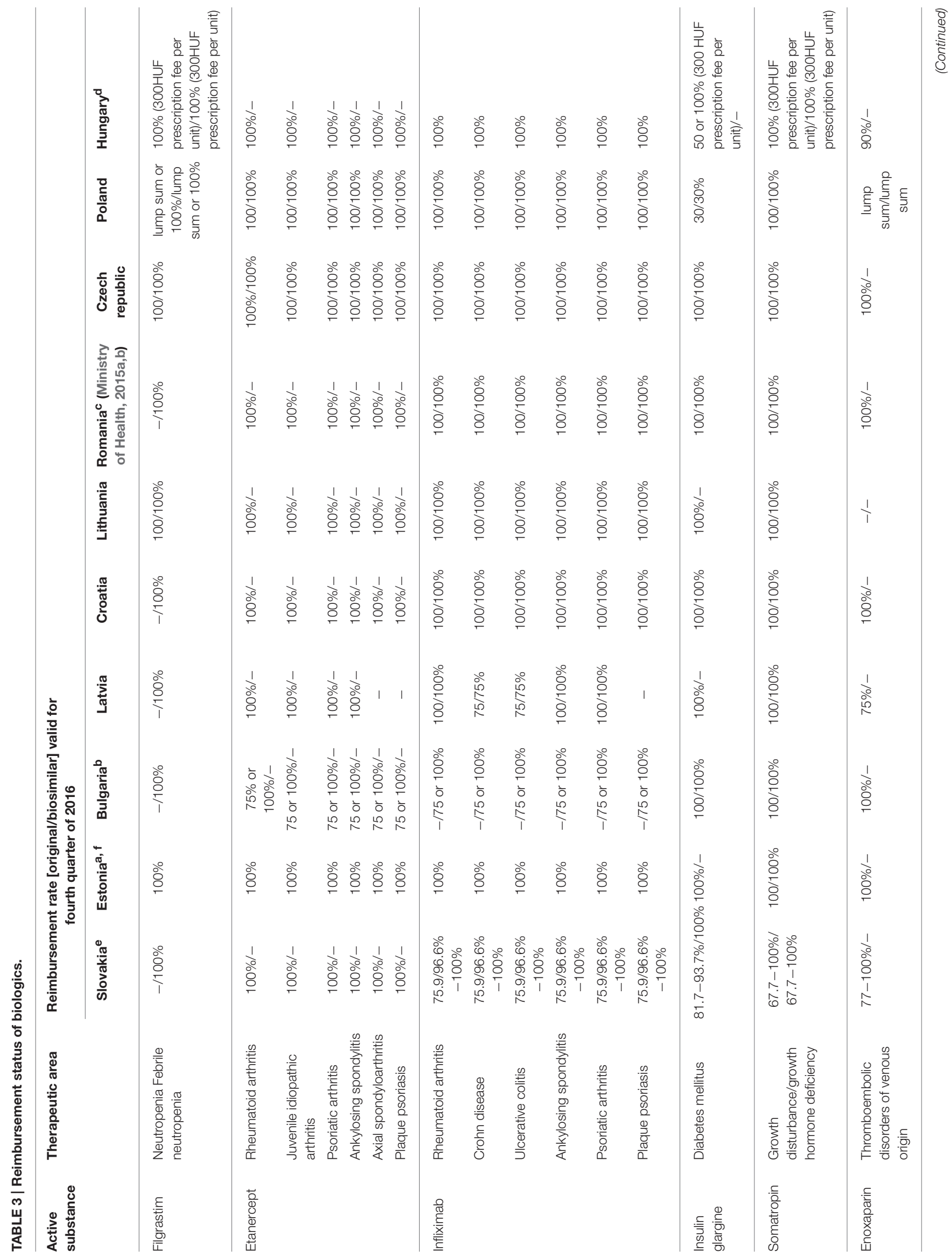


Kawalec et al.

Biosimilars Policy in CEE Countries

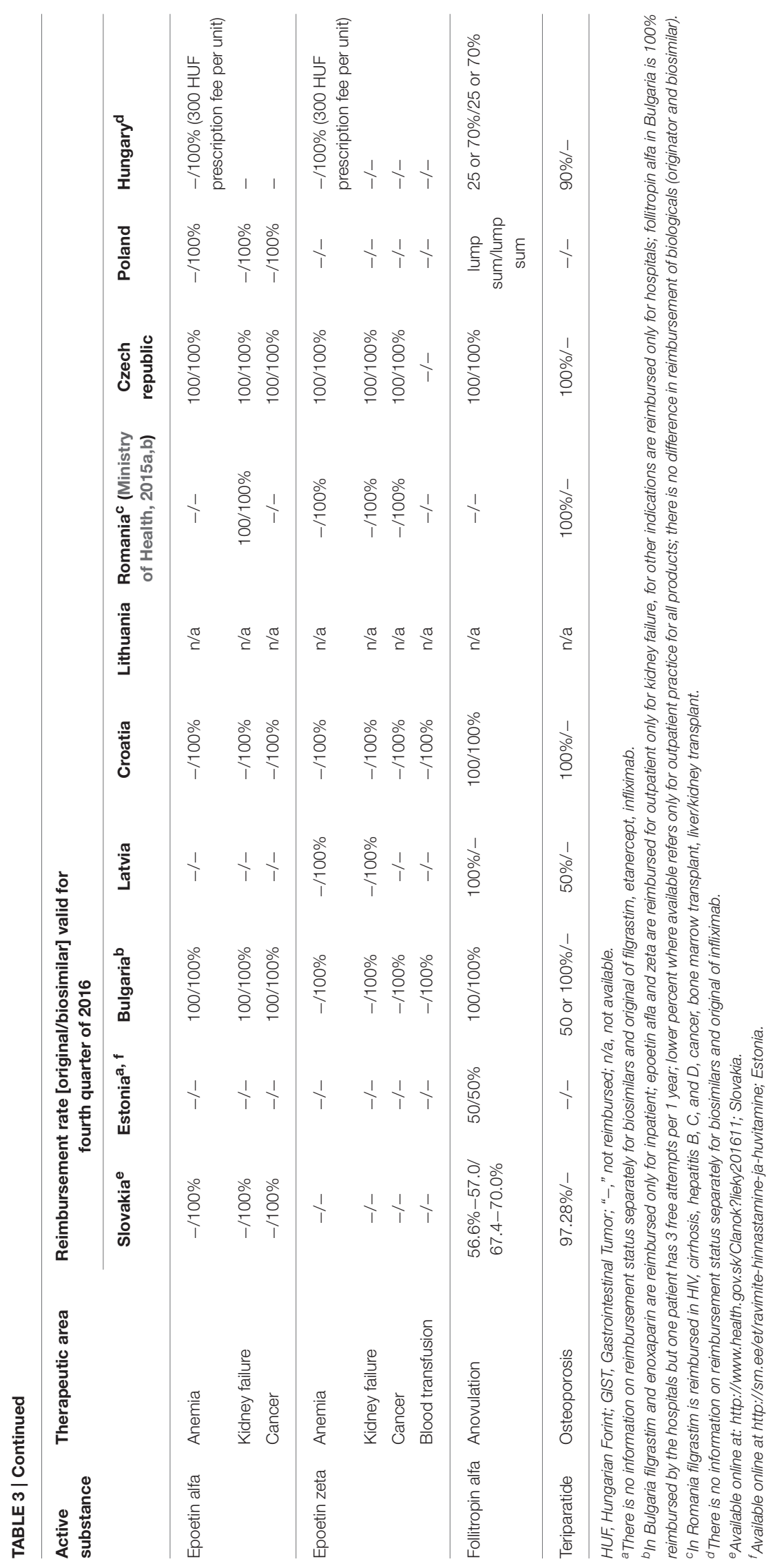

Frontiers in Pharmacology | www.frontiersin.org

June 2017 | Volume 8 | Article 288 
EUR in 2015 . On average, $81.8 \%$ of the value in 2014 and $78.7 \%$ of the value in 2015 was covered by the reimbursement of original drugs. Romania and Bulgaria were excluded from this analysis owing to lack of information on expenditures according to the type of drug-original or biosimilar. The shares of expenditures on the reimbursement of biosimilars and original drugs for each biologic in the years 2014 and 2015 are shown in Figures 1, 2, respectively.

On average, the lowest expenditure was shown for the reimbursement of epoetin zeta-1.8 million EUR in 2014 and
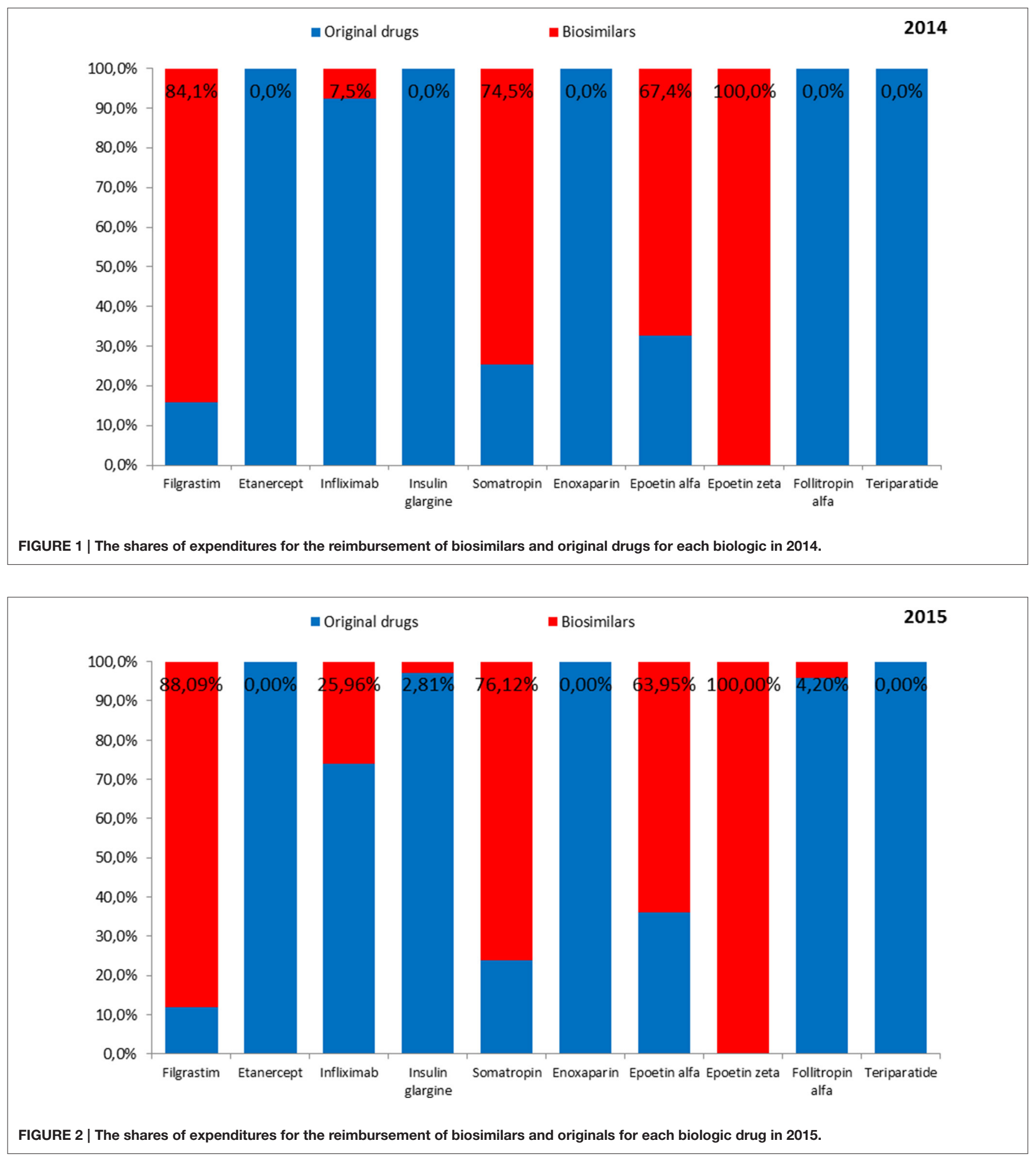
in 2015, and the highest-for enoxaparin (97.7 million EUR and 108.9 million EUR, respectively).

Biosimilars to etanercept, enoxaparin, and teriparatide were not reimbursed from public funds in any of the countries either in 2014 or 2015, while biosimilars to insulin glargine and follitropin alfa were not reimbursed in 2014. Therefore, no costs of reimbursement of those biosimilars were observed. Among original products, the lowest expenditure was shown for the reimbursement of epoetin alfa in the year 2014 (4.7 million EUR) and filgrastim in the year 2015 (4.0 million EUR) and the highest-for enoxaparin (97.7 million EUR in the year 2014 and 108.9 million EUR in the year 2015). Among biosimilars, the lowest reimbursement cost in 2014 was shown for epoetin zeta (1.8 million EUR) and in 2015-for follitropin alfa (0.5 million EUR). The highest reimbursement cost in 2014 and 2015 was shown for filgrastim (27.9 million EUR and 29.8 million EUR, respectively).

The shares of expenditures on the reimbursement of biosimilars in individual countries ranged from $8.0 \%$ in Estonia in 2014 to $38.1 \%$ in Lithuania in 2015. The data were presented separately for the years 2014 and 2015 in Figures 3, 4, respectively.

The highest expenditure on the reimbursement of biologic drugs was observed for Poland (117.0 million EUR in 2014
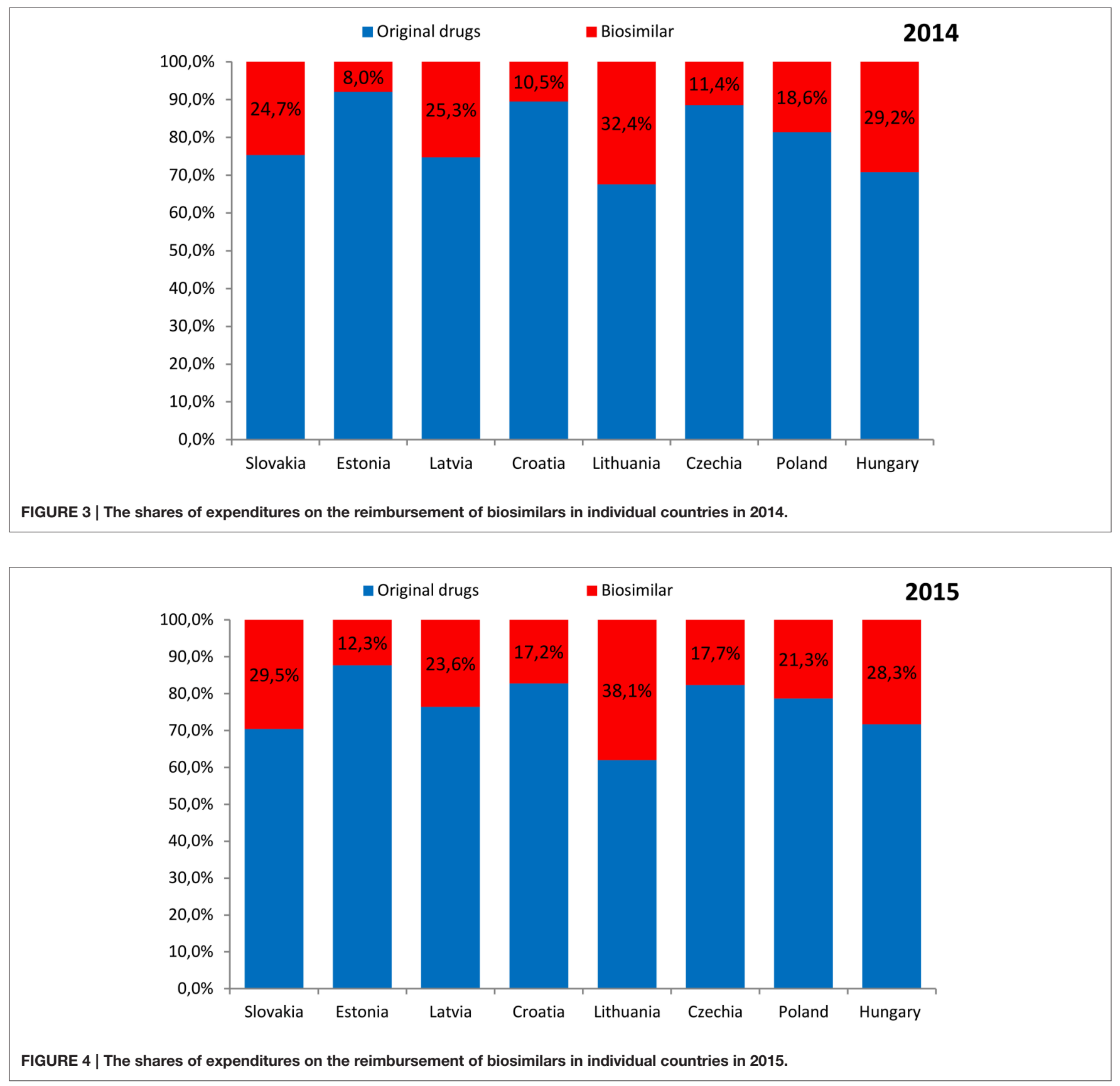
TABLE 4 | Total pharmaceutical and health care budgets in selected countries.

\begin{tabular}{|c|c|c|c|c|}
\hline \multirow[t]{2}{*}{ Country } & \multicolumn{2}{|c|}{ Total public pharmaceutical budget [EUR] } & \multicolumn{2}{|c|}{ Total public health care budget [EUR] } \\
\hline & 2014 & 2015 & 2014 & 2015 \\
\hline Slovakia & $884,000,000$ & $905,000,000$ & $3,882,000,000$ & $3,995,000,000$ \\
\hline Estonia & $109,753,000$ & $112,801,000$ & $664,071,000$ & $712,692,000$ \\
\hline Bulgaria & $416,168,185$ & $436,107,447$ & $2,037,894,823$ & $2,030,737,139$ \\
\hline Latvia & $118,930,000$ & $124,300,000$ & $725,013,000$ & $765,296,000$ \\
\hline Croatia & $667,500,000$ & $702,300,000$ & $3,190,000,000$ & $3,080,000,000$ \\
\hline Lithuania & $245,000,000$ & $253,000,000$ & $1,380,000,000$ & $1,470,000,000$ \\
\hline Romania & $1,838,000,000$ & $1,774,000,000$ & 4,892,000,000 & $4,775,000,000$ \\
\hline Czech Republic & 1,900,000,000 & $2,100,000,000$ & $9,000,000,000$ & $9,400,000,000$ \\
\hline Poland & $2,397,729,416$ & $2,500,319,654$ & $15,241,155,882$ & $16,245,277,755$ \\
\hline Hungary & 935,359, 295 & 1,000,955,147 & $5,011,650,360$ & $5,129,812,843$ \\
\hline
\end{tabular}

and 120.0 million EUR in 2015) and the lowest-for Romania (3.8 million EUR in 2014 and 3.7 million EUR in 2015). The highest expenditure on the reimbursement of original drugs was also observed for Poland (95.2 million EUR in 2014 and 94.5 million EUR in 2015), but the lowest-for Latvia (4.3 million EUR in 2014 and 5.1 million EUR in 2015). As for the reimbursement of biosimilars, the highest expenditure was revealed for Poland (21.8 million EUR in 2014 and 25.5 million EUR in 2015), and the lowest for Estonia (0.7 million EUR and 1.0 million EUR, respectively). Romania and Bulgaria were excluded from this analysis due to lack of information on expenditures according to the type of drug-original or biosimilar.

The total public pharmaceutical budget and total health care budget differed significantly between the countries. The lowest pharmaceutical and health care budgets were observed for Estonia and the highest-for Poland (see Table 4).

The expenditures on the reimbursement of biosimilars were presented as the percentage of the total pharmaceutical budget (Figure 5) and percentage of the total health care budget (Figure 6).

The expenditures on the reimbursement of biosimilars constituted the highest share of the total pharmaceutical budget and total health care budget in Hungary and Slovakia (1.7 and $0.4 \%$, respectively) and the lowest-in Croatia (0.3 and $0.1 \%$, respectively). The expenditures on the reimbursement of biosimilars as the share of the total pharmaceutical budget were higher in 2015 than in 2014 in all countries, except Slovakia and Hungary where the shares were lower in 2015. The expenditures on the reimbursement of biosimilars as the share of the total health care budget were also higher in 2015 than in 2014 in all countries, again except Slovakia and Hungary where the expenditures were higher in 2014.

\section{DISCUSSION}

Biological drugs are highly effective but also very costly. The high price of original drugs limits access to treatment, especially in low-income CEE countries. The widespread use of biosimilars might significantly reduce the cost of biologic treatment, also for individual patients. In this study we identified biologic drugs that have their biosimilar counterparts. We also discussed issues relating to the reimbursement and pricing of biosimilars, as well as their reimbursement status in CEE countries.

Our review revealed that the access to biologic treatment within specific drug groups was similar but the level of the patient's co-payment for particular drugs differed between the CEE countries. For example in Bulgaria for 12 of the indications (out of 25) biological therapy is co-paid by outpatients thus becoming unaffordable in case of high prices. The use of biosimilars was quite common, and the percentage of biosimilars used in the treatment of specific disease groups increased during the study period. No reimbursement was observed for etanercept, insulin glargine (in 2014), follitropin alfa (in 2014), teriparatide, and enoxaparin, which may suggest that no biosimilars to those drugs were available in those countries. Only for filgrastim, somatropin, and epoetin (alfa and zeta) the reimbursement costs were higher for biosimilars than for original drugs. For the remaining drugs, the share of reimbursement costs of biosimilars in the total reimbursement costs of a biologic drug did not exceed $26 \%$.

The shares of expenditures on the reimbursement of biosimilars in each country were similar and ranged from 8 to $32 \%$ in 2014 and from 12 to $38 \%$ in 2015. Expenditures on the reimbursement of biosimilars constituted from 0.3 to $1.7 \%$ of the total pharmaceutical budget in 2014 and was similar in the year 2015 (from 0.6 to $1.7 \%$ ), but the average value was higher in the year 2015 (1.1\% in the year 2014 compared with $1.2 \%$ in the year 2015). The shares of expenditures on the reimbursement of biosimilars in the total health care budget were also similar between the year 2014 and 2015-from $0.06 \%$ to $0.4 \%$ in 2014 and 2015, but again the average value was higher in the year 2015 $(0.20 \%$ in the year 2014 compared with $0.22 \%$ in the year 2015$)$.

In Hungary it is mandatory to use the cheapest available biological product in newly treated patients. For erythropoietin (EPO) and granulocyte colony-stimulating factors (GCSF), the so called biosimilar bids were introduced in 2012 (Hornyák et al., 2014). They are organized annually, and in each group of biologics the preferred drugs are those with the lowest price. As 


\section{Biosimilars as \% of total pharmaceutical budget}

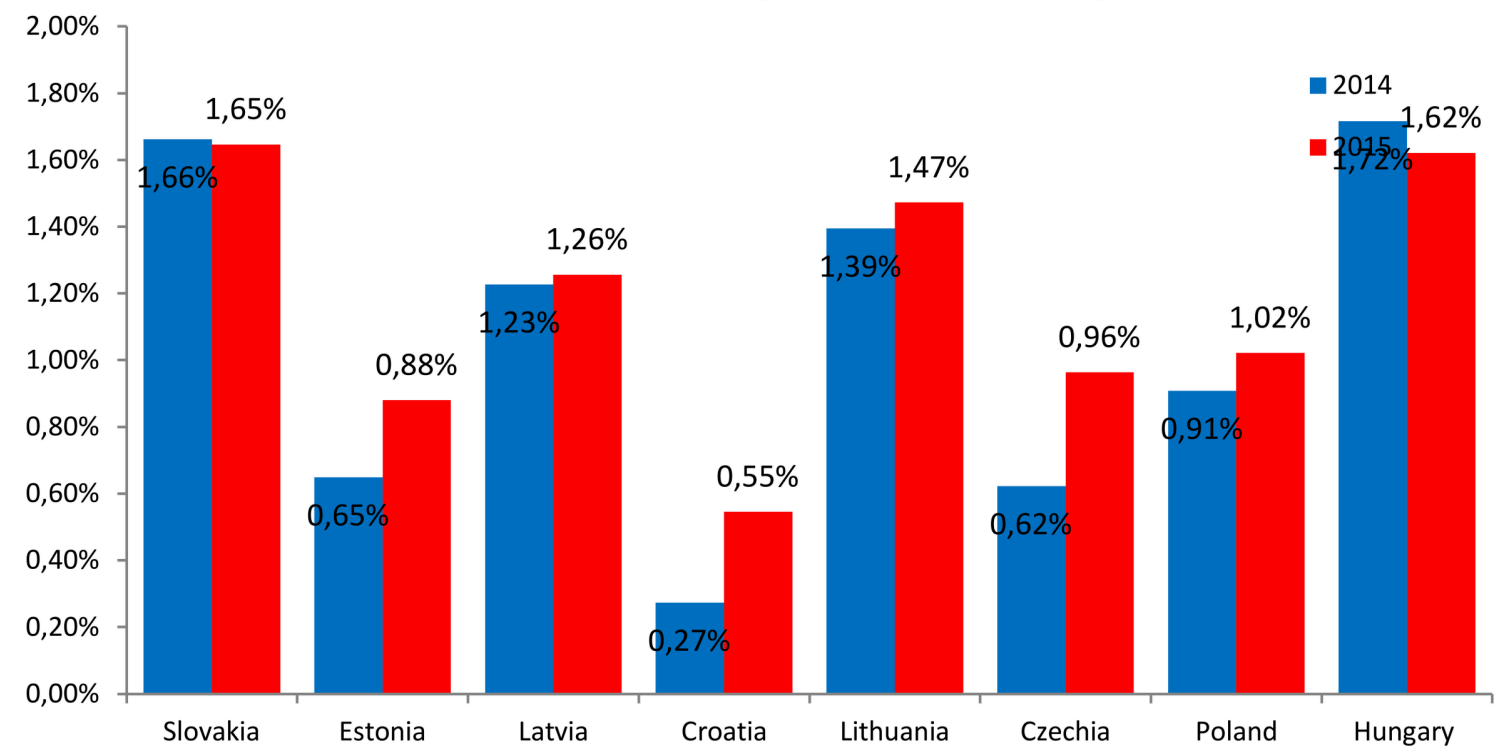

FIGURE 5 | Expenditures on the reimbursement of biosimilars as percentage of the total pharmaceutical budget.

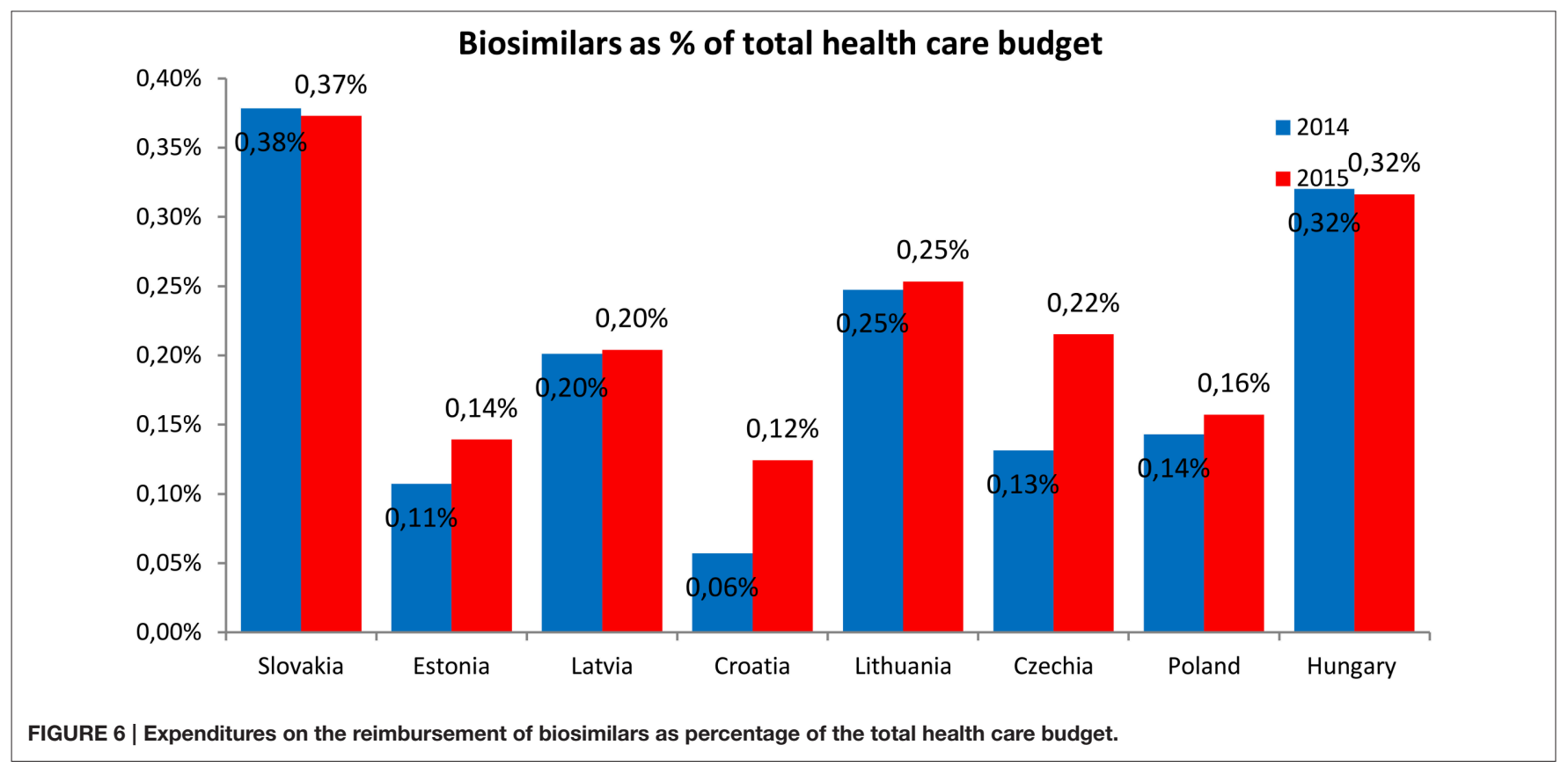

these products have $100 \%$ reimbursement, there is a prescription fee of only 300 Hungarian forints (HUF). Preferred drugs can be those with a price that is a maximum of $10 \%$ higher than the price of the reference product (i.e., the cheapest). Drugs with a price that is between 10 and $30 \%$ higher than that of the reference products are required to compensate the payer for the increased price with payback and are associated with a co-payment between 1,500 and 3,500 HUF. Increased co-payment is therefore a disincentive for patients to use these products. Drugs with a price that is $30 \%$ higher than that of the reference products are removed from the reimbursement list (i.e., positive list) 4 months after the biosimilar bid. Until then, they have a co-payment of 3,500 HUF. This allows some time for the patient and the treating physician to switch to a preferred product. Additionally, physicians are required to prescribe preferred biologics in a minimum $40 \%$ of the overall number of prescriptions. 
In Estonia, inpatient drugs, such as filgrastim, infliximab, and etanercept, are reimbursed by the hospital, and it is hospital authorities who decide, usually through tendering procedure, which products and at what prices will be acquired. The data are usually confidential and hospitals do not have to officially report which products they use in provision of health care services. Therefore, there are limited data on the reimbursement costs for Estonia, both for original drugs and biosimilars.

In Romania, the rate of reimbursement for biosimilar products is $100 \%$ of the reference price, that is, in general, the lowest price of products with the same active substance, the same strength and the same pharmaceutical form (biosimilars) available for reimbursement. The physician can choose a specific product and the difference between the drug's price and the reference price is paid by patient, but in the case of biosimilars this difference is 0 .

In Croatia the pricing and reimbursement process for biosimilars may sometimes require cost-effectiveness or costutility analysis ${ }^{3}$. In Latvia cost-minimization analysis and budget impact analysis are needed, while in Czech Republic an abbreviated clinical dossier should be presented, without economic evidence. In Czech Republic and Slovakia physicians prefer to treat new patients with biosimilars, while previously treated patients usually remain on the original product.

We performed a systematic review of medical databases (Medline via Pubmed and the Scientific Presentations database of International Society of Pharmaceoeconomics and Outcomes Research [ISPOR]) to identify relevant studies referring to biosimilar drug policy in CEE countries. However, we found no publications in line with the scope of our study, which emphasizes the novelty of our research. The review revealed only some papers on issues relating to the cost and reimbursement of biosimilars, but focusing mainly on the budget impact of biosimilar reimbursement or including a simplified discussion of an individual aspect (e.g., pricing) of biosimilar drug policy in individual CEE countries.

Hornyák et al. (2015) analyzed biosimilar bids of the Hungarian National Health Insurance Fund Administration (NHIFA) for colony-stimulating factor (CSF) products. Before the biosimilar bid, the NHIFA spent 7.49 billion HUF for health insurance reimbursement of CSF products, which decreased by $44 \%$ to 4.19 billion HUF in the first year after the bid. The analyses of the Hungarian price competition bid for biosimilar products showed a minor decline in the number of patients on treatment with CSF products, while the health insurance reimbursement of these drugs significantly decreased (Hornyák et al., 2014). Similar conclusions were drawn from the analysis of the biosimilar bids of the NHIFA for EPO products. The NHIFA spent 2.33 billion HUF for health insurance reimbursement of EPO products, which decreased by $47 \%$ to 1.23 billion HUF in the first year after the bid. Thus, the price competition bid of biosimilar products showed a health insurance reimbursement of these drugs to have significantly decreased (Nagy et al., 2015).

\footnotetext{
${ }^{3}$ Available online at: http://www.hzzo.hr/zdravstveni-sustav-rh/trazilica-zalijekove-s-vazecih-lista/arhiva-liste-lijekova (Accessed February13, 2017).
}

We also identified an abstract (Vogler et al., 2016) presenting the results of a survey analyzing the possible differences between pricing policies for generics and for biosimilar medicines in European countries including 25 EU countries (all except Ireland, Italy, and Luxembourg) as well as Albania, Belarus, Iceland, Norway, Serbia, Russia, Turkey, and Ukraine. While 23 of the 33 countries set the price of the generic in relation to the price of the originator, only 13 countries reported to do so for biosimilar medicines. Usually, the price difference between the biosimilar and originator medicine was set at a lower percentage rate than that between the generic and originator (e.g., 30\%-generics, 15\%-biosimilars in Croatia; 50\%-generics, 30\%-biosimilars in Lithuania; 35\%-generics, 20\%-biosimilars in Romania). It occurred that only Austria, Latvia, and Turkey applied the same price difference for generic and biosimilar medicines. The Netherlands have been tendering for generics in the outpatient sector during the last decade, but biosimilars have been included in tenders only recently. The authors concluded that European countries tend to apply similar pricing policies for generic and biosimilar medicines (Vogler et al., 2016).

Another study (Brodszky et al., 2014, 2016) analyzed the budget impact of introducing biosimilar infliximab for the treatment of patients with Crohn disease (CD) in the health care systems of 6 CEE countries: Bulgaria, Czech Republic, Hungary, Poland, Romania, and Slovakia. This budget impact model estimated the potential impact of biosimilar infliximab on health care budget over 3-year timeframe from the third-party payer perspective. The model tracked movement of the population of patients with CD between main states: (1) immune therapy, (2) infliximab, (3) biosimilar infliximab, and (4) adalimumab. Switching between biologics and biosimilar infliximab was also considered. A price difference of $25 \%$ was assumed for biosimilar infliximab compared to the originator. Budget impact was calculated as a difference in the total cost of scenarios with and without biosimilar infliximab. Over the 3-year period, with gradually interchanging $80 \%$ of infliximab to biosimilar, infliximab was expected to lead to a net benefit of 16,635,000 EUR compared with the scenario in which biosimilar infliximab would not be available. In the scenario in which interchangeability was not allowed, the budget savings amounted to 7,842,000 EUR. It was revealed that if budget savings were spent on the reimbursement of additional biosimilar infliximab treatments, 722-1,530 additional patients with CD could be treated in the 6 countries (Brodszky et al., 2016). Based on these calculations, the introduction of biosimilar infliximab treatment for $\mathrm{CD}$ in $\mathrm{CEE}$ countries should bring about substantial cost savings or increase the number of patients with access to biologic therapy (Brodszky et al., 2014, 2016).

Rovira et al. (2013) described the development of biosimilars in 24 EU countries, Norway and Switzerland. Authors tried to identify the key parameters associated with biosimilars market dynamics and included three molecules as references: somatropin, epoetin, filgrastim. The results of this analysis showed that the market share of biosimilars for included molecules has risen rapidly in the years from 2007 to 2010. The key drivers responsible for market dynamics were: generics price control policy, countries' gross national income and expenditure 
on health, pharmacists' generics substitution and medicines' price level index. Introduction of biosimilars resulted in reduction of biologics' cost, however this reduction seems to be smaller than for conventional generics.

Authors of another study (Remuzat et al., 2017) also tried to identify the key drivers for market penetration of biosimilars in Europe. Ten EU member states were included in the analysis and 20 biosimilars. It was concluded, that incentive policies applied to biosimilars and biosimilars' uptakes were heterogeneous across analyzed countries. Incentive policies and the date of first biosimilar market entry were positively correlated with biosimilar uptake, while pharmaceutical expenditure per capita and the highest generic uptake were inversely correlated with biosimilar uptake. Also the average generic price discount over originator and the number of biosimilars seemed to influence the biosimilar uptake, however biosimilar price discounts had no impact on the uptake.

Grabowski et al. in their study (Grabowski et al., 2014) analyzed the experiences with biosimilars to epoetin alfa and filgrastim in $5 \mathrm{EU}$ countries. One major finding was that although the EU has a common regulatory system for approving biosimilars, differences in reimbursement practices and incentives as well as variations in medical practices are observed across countries. It was observed that biosimilar price discounts were likely to be modest compared to generics. Another finding was that cost savings from the introduction of biosimilars in the European countries have been tempered by the fact that competition has been limited to the first-generation reference products. Dynamic competition through the market entry of next-generation biologics is an important consideration in analyzing the market impact of biosimilars and their potential savings to the health-care system.

In countries of the EU as well as outside the EU evaluations on costs of biologic drugs were also performed (Jakovljevic,

\section{REFERENCES}

Brodszky, V., Gulacsi, L., Balogh, O., Baji, P., Rencz, F., and Péntek, M. (2014). Budget impact analysis of biosimilar infliximab for the treatment of crohn's disease in six central eastern European countries. Value Health 17:A364. doi: 10.1016/j.jval.2014.08.805

Brodszky, V., Rencz, F., Péntek, M., Baji, P., Lakatos, P. L., and Gulácsi, L. (2016). A budget impact model for biosimilar infliximab in Crohn's disease in Bulgaria, the Czech Republic, Hungary, Poland, Romania, and Slovakia. Expert Rev. Pharmacoecon. Outcomes Res. 16, 119-125. doi: 10.1586/14737167.2015.1067142

Derbyshire, M. (2015). Patent expiry dates for best-selling biological. Gene. Biosimilars Initiat. J. 4, 178-179. doi: 10.5639/gabij.2015.0404.040

ESzCsM Decree (2017). 32/2004. (IV. 26.) ESzCsM Decree, Concerning the Reimbursement of Medicinal Products. Available online at: http://net.jogtar.hu/ jr/gen/hjegy_doc.cgi?docid=A0400032.ESC (Accessed February 13, 2017).

European Medicines Agency (2017). European Public Assessment Reports. Available online at: http://www.ema.europa.eu/ema/index. jsp?curl=pages\%2Fmedicines\%2Flanding\%2Fepar_search.jsp\&mid= WC0b01ac058001d124\&searchTab=searchByAuthType\&alreadyLoaded $=$ true\&isNewQuery=true\&status $=$ Authorised\&keyword=Enter+keywords\& searchType=name\&taxonomyPath $=\&$ treeNumber $=\&$ searchGenericType $=$ biosimilars\&genericsKeywordSearch=Submit (Accessed February 13, 2017).
2014) but with no sophisticated analyses of market share and reimbursement costs between original biologics and biosimilars corresponding to results of our study.

\section{CONCLUSIONS}

Our study revealed that biosimilars significantly influenced the reimbursement systems in the selected CEE countries. Expenditures on the reimbursement of biosimilars are increasing, and the access of patients to this type of treatment is improving. The share of expenditures on the reimbursement of biosimilars in the considered CEE countries increased during the study period, along with an increase in expenditures on the reimbursement of biosimilars as percentage of the total pharmaceutical budget. The considered CEE countries are similar in terms of the requirements for the pricing and reimbursement of biosimilars.

\section{AUTHOR CONTRIBUTIONS}

PK conceived the conception and design of the study, including protocol and questionnaires preparation, and coordinated the project. PK contributed in acquisition of data. PK and ES carried out the data management, statistical analysis, interpretation of data and prepared the draft of the manuscript. TT, JS, AT, MD, GP, ZR, AM, AH, and PD collected and provided input data for corresponding countries. All authors contributed to editing the manuscript and approved the final version submitted for publication. PK is the guarantor.

\section{ACKNOWLEDGMENTS}

The study was self-financed. The authors would like to thank Karoline Garuoliene for providing relevant data for our project relating to Lithuania.
Grabowski, H., Guha, R., and Salgado, M. (2014). Biosimilar competition: lessons from Europe. Nat. Rev. Drug Discov. 13, 99-100. doi: 10.1038/nrd4210

Hornyák, L., Nagy, Z., Tálos, Z., Endrei, D., Ágoston, I., Csákvári, T., et al. (2014). Experiences with price competition of biosimilar drugs in Hungary. Acta Pharm. Hung. 84, 83-87. doi: 10.1016/j.jval.2014.08.1018

Hornyák, L., Nagy, Z., Tálos, Z., Endrei, D., Ágoston, I., Csákvári, T., et al. (2015). Experiences with price competition of biosimilar drugs in hungary in case of colony-stimulating factor products. Value Health 18:A477. doi: 10.1016/j.jval.2015.09.1285

IMS (2016). Delivering on the Potential of Biosimilar Medicines. The Role of Functioning Competitive Markets. IMS Institute for Healthcare Informatics. Available online at: http://www.imshealth.com/files/web/IMSH\%20Institute/ Healthcare\%20Briefs/Documents/IMS_Institute_Biosimilar_Brief_March_ 2016.pdf (Accessed February 13, 2017).

Jakovljevic, M. B. (2014). Oncology monoclonal antibodies expenditure trends and reimbursement projections in the emerging Balkan market. Farmeconomia Health Econ. Ther. Pathways 15, 27-32. doi: 10.7175/fe.v15i1.909

Kawalec, P., and Malinowski, K. P. (2016). Relating Health Technology Assessment recommendations and reimbursement decisions in Poland in years 2012-2014, a retrospective analysis. Health Policy 120, 1240-1248. doi: 10.1016/j.healthpol.2016.09.021

Long, D. (2015). "Perspective on the evolving biosimilars landscape," in HDMA Distribution Management Conference and EXPO (Orlando, FL). 
Ministry of Health (2011). [Decree No. 422/2011 of the Ministry of Health of the Slovak Republic on the Details of the Pharmacoeconomic Analysis of Medicine] Vyhláškač. 422/2011 MZ SR o Podrobnostiach Farmako-Ekonomického Rozboru Lieku. Available online at: http://www.zakonypreludi.sk/zz/2011-422

Ministry of Health (2013). Ministry of Health Order No. 724/2013 Regarding the Approval of Criteria for Evaluation of Medical Technologies, the Documents to be Submitted by Applicants, the Process and the Methodology Used to Assess the Drugs, and the New Indications to be Included on the Reimbursement List. Bucarest: Romanian Official Gazette No. 339 (Accessed June 10, 2013).

Ministry of Health (2014). Ministry of Health Order No. 861/2014 (BC 17.03.2015) Regarding the Approval of Criteria for Evaluation of Medical Technologies, the Documents to be Submitted by Applicants, the Process and the Methodology Used to Assess the Drugs, the New Indications to be Included on the Reimbursement List, and the Criteria for Exclusion of Drugs from the List. Bucarest: Romanian Official Gazette No. 557. (Accessed July 28, 2014).

Ministry of Health (2015a). Ministry of Health Order No. 1505/29.12.2015 Regarding the Modification of National Health Insurance House Order No. 944/2015. Bucarest: Ministry of Health.

Ministry of Health (2015b). 1750/30.12.2015 and National Health Insurance House Order No. 1506/29.12.2015 Regarding the Approval of the Calculation, the List of Trade Names and Prices of Drugs for Patients in National Health Programs and the Methodology for their Calculation. Ministry of Health.

Mulcahy, A. W., Predmore, Z., and Mattke, S. (2014). The Cost Savings Potential of Biosimilar Drugs in the United States. RAND Corporation. Available online at: http://www.rand.org/pubs/perspectives/PE127.html

Nagy, Z., Hornyák, L., Tálos, Z., Endrei, D., Ágoston, I., Csákvári, T., et al. (2015). Experiences with price competition of biosimilar drugs in Hungary in case of erythropoietin products. Value Health 18:A513. doi: 10.1016/j.jval.2015.09.1485

Ornes, S. (2015). Core concepts: biosimilars. Proc. Natl. Acad. Sci. U.S.A. 112, 15261-15262. doi: 10.1073/pnas.1520698112
Panteli, D., Arickx, F., Cleemput, I., Dedet, G., Eckhardt, H., Fogarty, E., et al. (2016). Pharmaceutical regulation in 15 European countries review. Health Syst. Transit. 18, 1-122.

Regulation of Ministry of Social Affairs (2017). Procedure for Drafting and Amendment of a List of Medicinal Products of the Estonian Health Insurance Fund and the Content of Criteria for Establishing the List and Evaluators of Compliance with the Criteria. Available online at: https://www.riigiteataja.ee/ en/eli/ee/SOM/reg/516062015002/consolide (Accessed February 13, 2017).

Remuzat, C., Dorey, J., Cristeau, O., Ionescu, D., Radière, G., and Toumi M. (2017). Key drivers for market penetration of biosimilars in Europe. J. Mark. Access Health Policy 5:1272308. doi: 10.1080/20016689.2016.1272308

Rovira, J., Lindner, L., Gimenez, E., Espín, J., de Labry, A. O., and García, L. (2013). Biosimilars in the European market. Gene. Biosimilars Init. J. 1, 30-35. doi: 10.5639/gabij.2013.0201.012

Vogler, S., Schneider, P., Gombocz, M., and Zimmermann, N. (2016). "Differences in pricing policies for generic and biosimilar medicines," in ISPOR 19th Annual European Congress (Vienna: Scientific Presentation Database). Available online at: www.ispor.org

Conflict of Interest Statement: The authors declare that the research was conducted in the absence of any commercial or financial relationships that could be construed as a potential conflict of interest.

Copyright (c) 2017 Kawalec, Stawowczyk, Tesar, Skoupa, Turcu-Stiolica, Dimitrova, Petrova, Rugaja, Männik, Harsanyi and Draganic. This is an open-access article distributed under the terms of the Creative Commons Attribution License (CC BY). The use, distribution or reproduction in other forums is permitted, provided the original author(s) or licensor are credited and that the original publication in this journal is cited, in accordance with accepted academic practice. No use, distribution or reproduction is permitted which does not comply with these terms. 